\title{
Adipose-derived mesenchymal stem cells and platelet-rich plasma synergistically ameliorate the surgical-induced osteoarthritis in Beagle dogs
}

Sungho Yun ${ }^{1}$, Sae-Kwang $\mathrm{Ku}^{2}$ and Young-Sam Kwon ${ }^{1,3^{*}}$

\begin{abstract}
Background: The purpose of this study is to investigate the clinical effects of platelet-rich plasma (PRP) and adipose-derived mesenchymal stem cell (MSC) as the fundamental treatment of osteoarthritis (OA).

Methods: Twenty four Beagle dogs were used as cranial cruciate ligament transection models. The dogs were divided into four groups $(n=6)$ according to the intra-articular injection materials: the control group with phosphate-buffered saline (PBS), the PRP group with PRP, the MSC group with MSCs emerged in PBS, and the MSC and PRP co-treatment (MP) group with MSCs and PRP.

Results: Lameness score, focal compression strength, articular extracellular matrix (ECM) compositions, histopathology, and real-time PCR were used to evaluate the effects of PRP and MSCs on canine OA. In the order Of MP, PRP, and MSC group, these all showed positive effects on the evaluated categories. The lameness scores were lower, and the focal compression strengths of the affected femoral articular surface cartilages were higher than those in the OA control group. Also, the inflammatory changes, when evaluated with Mankin scoring and histomorphologic examination, were significantly ameliorated with the treatment of PRP and/or MSCs. The glycosaminoglycan and collagen composition of extracellular matrix was more favorable in the test groups. The ECM-related genes significantly increased through the up-regulation, while the protein expressions of inflammatory cytokines were decreased through the inhibitory effects of PRP and MSCs on chondrocyte apoptosis and inflammatory cytokines.
\end{abstract}

Conclusions: Taken together, this study suggests that PRP and MSCs treatments have a beneficial effect on OA via the stimulation of ECM synthesis and chondrocyte proliferation and via the inhibition of inflammatory reaction.

Keywords: Adipose-derived MSC, Canine, Osteoarthritis, Platelet-rich plasma

\section{Background}

Osteoarthritis $(\mathrm{OA})$ is the most common clinical syndrome of joint pain and dysfunction, accompanied by varying degrees of functional limitation and the reduced quality of life. Because it is mostly irreversible and progressive, OA joint consequently loses their cartilage layer [1].

\footnotetext{
* Correspondence: kwon@knu.ac.kr

${ }^{1}$ Department of Veterinary Surgery, College of Veterinary Medicine, Kyungpook National University, Daegu 702-701, Republic of Korea

${ }^{3}$ Stem Cell Therapeutic Research Institute, Kyungpook National University,

Daegu 702-701, Republic of Korea

Full list of author information is available at the end of the article
}

The most ideal treatment of OA is focused on blocking the catabolic activity of cartilage and enhancing regeneration of normal cartilage. Until now, therapies for the OA commonly focused on the palliation of pain and discomfort, improvement on functional movement, and prevention of further degeneration. Thus, the primary approach in the clinical treatment of OA involves the extensive use of NSAIDs, analgesics, and hyaluronan which allows the brief symptomatic relief but provides no apparent disease-modifying effect [2-4]. Therefore, there is a critical need for the development of the alternative agents that can fundamentally prevent the destruction of cartilages or stimulate its proper repair. In 
these aspects, various efforts have been tried to search for the effective cartilage-preserving methods with cell sources.

To sum up, the isolated chondrocyte expansion and implantation method is regarded as the fundamental solution. However, the main concern of the most cultured chondrocytes is losing the characteristics of producing hyaline-like cartilage $[5,6]$. In a canine model, it has been reported that cultured autologous chondrocytes failed to return to the normal hyaline cartilage [7].

In human, the intra-articular injection of $1.0 \times 10^{8}$ cells of adipose-derived mesenchymal stem cell (MSC) could improve the function, reduce the pain, and regenerate the hyaline-like cartilage [8]. MSCs are typically not observed in synovial fluid. However, MSCs appear in synovial fluid in the OA condition, and they are thought to play an important role in the regeneration of damaged tissue and have anti-inflammatory effect [9]. As the patient ages, the quality and quantity of MSCs decrease and there is a reduction of their ability to proliferate and differentiate. Also, the depletion of healthy MSCs is regarded as one of the reasons worsening OA [10]. For these reasons, it is believed that the direct administration of MSCs could promote the positive role of them by preventing their depletion and improving cartilage regeneration [11].

The platelet-rich plasma (PRP) is defined as the plasma with the platelet population of more than $1.0 \times 10^{6}$ cells/ $\mu \mathrm{l}$, and it has typically four- to eightfold more platelets than the normal plasma [12]. PRP has various growth factors such as platelet-derived growth factor and transforming growth factor beta [13]. It has been well known that PRP has angiogenic, antiinflammatory, and anti-catabolic effects [13, 14]. It has also been reported that transforming growth factor beta and fibroblast growth factor from PRP have an anabolic effect on cartilage metabolism [15]. These factors not only regulate the cell migration and proliferation but also enhance the wound healing and extracellular matrix (ECM) remodeling via the stimulation of angiogenesis [16, 17].

Based on the previous studies, it is hypothesized that the PRP could have a synergistic effect on the cartilage regeneration with the combination of MSCs. Therefore, the purpose of this study is to examine the effect of PRP and MSCs on the morphologic change and regeneration of articular cartilage in the inflammation process using canine OA model.

\section{Methods}

\section{PRP preparation}

Autologous PRP was prepared in each dog using double spin method. Fifty milliliters of fresh blood was collected with $7 \mathrm{ml}$ of acid citrate dextrose formula A. Then, the blood was centrifuged at $1200 \mathrm{rpm}$ for $10 \mathrm{~min}$ into three layers: plasma, buffy coat, and red blood cell. After the plasma and buffy coat were separated into a new tube, the mixture was centrifuged at $2500 \mathrm{rpm}$ for $10 \mathrm{~min}$. Discarding the supernatant, only the lower $20 \%$ of the plasma was harvested. The collected plasma (PRP) was tested using complete blood cell count test (Cell-Dyne, Abbott Lab., USA) to make sure it had $1.0 \times 10^{6}$ platelets/ $\mu \mathrm{l}$ or more. All prepared PRP in this study were used within $6 \mathrm{~h}$.

\section{Adipose-derived mesenchymal stem cell isolation and culture}

Approximately $15 \mathrm{~g}$ of fat tissue was aseptically collected from the flank of a dog. It was rinsed with phosphatebuffered saline (PBS) several times to remove any remaining anesthetic agent and blood. Rinsed fat tissue was then digested using $0.075 \%$ collagenase type I (collagenase type $1 \mathrm{~A}$, Sigma-Aldrich, USA) in $37{ }^{\circ} \mathrm{C}$ waterchamber for $2 \mathrm{~h}$ with shaking or inverting every $30 \mathrm{~min}$. After adding the equal volumes of Dulbecco modified Eagle medium and $10 \%$ fetal bovine serum, it was centrifuged at $1200 \mathrm{rpm}$ for $10 \mathrm{~min}$. The supernatant and digested lipids were discarded. The cell pellet was washed with PBS, and it was filtered through $100-\mu \mathrm{m}$ nylon mesh. After centrifuging at the same condition, the cells were suspended into a $100 \times 20 \mathrm{~mm}$ cell culture dish with lowglucose Dulbecco modified Eagle medium and $10 \%$ fetal bovine serum. After $24 \mathrm{~h}$, non-adherent cells and debris were washed with PBS, and cell culture media was replaced twice per week. MSCs were collected and used between passage 1 and 2 in all the experiments of this paper. The flow cytometry analysis with established MSCs was performed, and obtained MSCs were negative for cluster of differentiation (CD) 34 and CD45 and strongly positive for CD29 and CD44 (Additional file 1: Fig. S6).

\section{The canine model of cranial cruciate ligament transection} The procedures were approved by Institutional Animal Care and Use Committees of Kyungpook National University. Twenty four physically healthy Beagle dogs were used in this experiment. The weights of dogs were $7.7 \pm$ $1.1 \mathrm{~kg}$ (mean \pm standard deviation), and ages were between 2-3 years old. Under the anesthetic state, the cranial cruciate ligament of a right hind limb was excised with a no. 11 scalpel blade. The connective tissues and skin were sutured with routine procedure. Analgesics (tramadol $8 \mathrm{mg} / \mathrm{kg}$ BID, subcutaneous) and antibiotics (enrofloxacin $5 \mathrm{mg} / \mathrm{kg}$ SID, subcutaneous) were administrated for 3 days after the surgery. After a week for soft tissue healing, each dog regularly walked for 10 min per day for 2 months. Then, treatment was given every week for 1 month. Another 2 months later, the dogs were sacrificed and stifle samples were collected. 


\section{MSC and PRP application}

After the canine OA model, the subjects were treated every week for 1 month with an intra-articular injection with each material according to the groups: the control group with $1 \mathrm{ml}$ of PBS, the PRP group with $1 \mathrm{ml}$ of PRP, the MSC group with $1.0 \times 10^{7}$ MSCs in $1 \mathrm{ml}$ of PBS, and the MSC and PRP co-treatment (MP) group with $1.0 \times 10^{7} \mathrm{MSCs}$ in $1 \mathrm{ml}$ of PRP. The contralateral stifle joint of the dogs in control group were used as a sham group in a histopathological examination, and no treatment material was given.

\section{Evaluations}

\section{Lameness score}

The lameness score was measured before the surgery and by every month after the surgery. All dogs had normal gait and no lameness before surgery. Previously described scoring system was used [18], and is as followed: 0 , no detectable lameness; 1 , minor lateral weight shift but no lameness at walk and trot; 2, no lameness at a walk but mild lameness at a trot; 3 , mild lameness at a walk and significant lameness at trot; 4, non-weight bearing at a trot; and 5, non-weight bearing at walk and standing. As a blind test, three veterinarians assessed the grade of lameness.

\section{The measurement of focal compressive strengths}

After sacrifice and sampling, the ex vivo compression strengths of the femoral and tibial articular surfaces $(0.2 \mathrm{~mm})$ of each sample were detected with a computerized testing machine (SV-H1000, Japan Instrumentation System Co., Tokyo, Japan) as $N$ (Newton). The measured points were central region of the medial femoral and tibial condyle.

\section{Histological process}

The articular cartilages of central region of the lateral femoral and tibial condyle were taken from knee joints of each group, and they were separately fixed in $10 \%$ neutral buffered formalin (NBF), and then decalcified in decalcifying solution $(24.4 \%$ formic acid and $0.5 \mathrm{~N}$ sodium hydroxide) for 14 days (mixed decalcifying solution was exchanged once a day for 14 days). Each femoral and tibial articular surface cartilage was longitudinally trimmed, then embedded in paraffin, sectioned $(3-4 \mu \mathrm{m})$ using tungsten bladder equipped automated polycut microtome (Model RM2255, Leica, Wetzlar, Germany), and stained with Sirius red stain for cartilaginous tissues. In each prepared histological samples, the histological profiles were interpreted under a light microscope (Model Eclipse $80 i$, Nikkon, Tokyo, Japan) as blinds to group distribution when this analysis was made.

\section{Analysis of ECM compositions}

Some parts of the cartilage on the femoral and tibial articular surface taken from the knee joints of each group were separately lyophilized to obtain the dry weight. Then, the piece was digested and used for glycosaminoglycan (GAG) and collagen (COL) analyses [19, 20]. The concentration of GAG was determined through the dimethyl-methylene blue sulfated GAG assay using a UV/ VIS spectrophotometer (Optizen Pop, Mecasys, Daejeon, Korea). Collagen content was determined by Erlich's hydroxyproline assay [21]. The hydroxyproline content was converted to the collagen content using the following equation: ( $\mu \mathrm{g}$ hydroxyproline $\times$ dilution factor) $/ 0.13=\mu \mathrm{g}$ collagen, based on the fact that hydroxyproline representing approximately $13 \%$ of the amino acid content of collagen in the human meniscus [22]. The concentrations of GAG and collagen were standardized to tissue dry weight and expressed as microgram per milligram to allow comparison among the experimental groups.

\section{ECM-related chondrogenic gene mRNA expressions}

The SOX9 and aggrecan messenger RNA (mRNA) expressions on the femoral and tibial articular surface cartilages were detected using real-time PCR. Briefly, RNA was extracted using Trizol reagent (Invitrogen, Carlsbad, CA, USA). The RNA concentrations and quality were determined by CFX96 ${ }^{\text {TM }}$ Real-Time System (Bio-Rad, Hercules, CA, USA). To remove contaminating DNA, samples were treated with recombinant DNase I (DNAfree; Ambion, Austin, TX, USA). RNA was reverse transcribed using the reagent High-Capacity cDNA Reverse Transcription Kit (Applied Biosystems, Foster City, CA, USA) according to the manufacturer's instructions. The cDNA strand was synthesized from the total RNA and then the mixture of primers and the cDNA products was amplified by PCR, and the conditions of PCR amplification were $58{ }^{\circ} \mathrm{C}$ for $30 \mathrm{~min}, 94{ }^{\circ} \mathrm{C}$ for $2 \mathrm{~min}, 35$ cycles of $94{ }^{\circ} \mathrm{C}$ for $15 \mathrm{~s}, 60{ }^{\circ} \mathrm{C}$ for $30 \mathrm{~s}, 68{ }^{\circ} \mathrm{C}$ for $1 \mathrm{~min}$, and then $72{ }^{\circ} \mathrm{C}$ for $5 \mathrm{~min}$. Analysis was carried out using ABI Step One Plus Sequence Detection System (Applied Biosystems, Foster City, CA, USA), and their expression levels were calculated as relative to sham group. The expression of glyceraldehyde 3-phosphate dehydrogenase (G3PDH) mRNA was used as a control for tissue integrity in all of the samples. The sequences of the PCR oligonucleotide primers were as listed in Table 1.

\section{BrdU uptake measurement}

To assess the effects of MSC and PRP or their cotreatment (MP) on the proliferation of cells within the dog knee joints, proliferating cells were labeled by an intraperitoneal injection of 5-bromo-2'-deoxyuridine (BrdU). Dogs were given intraperitoneal injections of BrdU (Sigma-Aldrich, St. Louise, MO, USA) $50 \mathrm{mg} / \mathrm{kg}$, 
Table 1 Oligonucleotides for real-time PCR used in this study

\begin{tabular}{llll}
\hline Target & 5'-3' $^{\prime}$ & Sequence & $\begin{array}{l}\text { NCBI accession } \\
\text { no. }\end{array}$ \\
\hline SOX9 & Sense & AAGCTCTGGAGGCTGCTGAA & NM_001002978.1 \\
& Antisense & ACTTGTAATCCGGGTGGTCTTC & \\
Aggrecan & Sense & CTATGAGGACGGCTTCACC & U65989.2 \\
& Antisense & AGACCTCACCCTCCATCTCC & \\
G3PDH & Sense & TATTGTCGCCATCAATGACC & NM_01003142 \\
& Antisense & TACTCAGCACCAGCATCACC & \\
& &
\end{tabular}

$P C R$ polymerase chain reaction, $N C B I$ National Center for

Biotechnology Information

in a volume of $1 \mathrm{ml} / \mathrm{kg}$ and dissolved in saline, and the animals were sacrificed $72 \mathrm{~h}$ later. BrdU uptakes were detected with immunohistochemistry using an antiBrdU antibody, as shown in histomorphometry sections.

\section{Immunohistochemistry}

Immunoreactivity for BrdU as cell proliferating marker was considered using purified primary antibody with avidin-biotin-peroxidase complex (ABC). Immunoreactivities in the prepared femoral and tibial surface cartilage tissues against caspase-3, cleaved poly(ADP-ribose) polymerase (PARP), tumor necrosis factor (TNF)- $\alpha$, cyclooxygenase (COX)-2, interleukin (IL)- $1 \beta$, interferon (IFN)- $\gamma$, and inducible nitric oxide synthase (iNOS) were also additionally observed after treatment MSCs, PRP, or their combination. Briefly, endogenous peroxidase activity was blocked by incubated in methanol and $0.3 \% \mathrm{H}_{2} \mathrm{O}_{2}$ for $30 \mathrm{~min}$, and non-specific binding of immunoglobulin was blocked with normal horse serum blocking solution for $1 \mathrm{~h}$ in humidity chamber after epitope retrievals by pretreatment of trypsin (Sigma-Aldrich, St. Louise, MO, USA) and $2 \mathrm{~N} \mathrm{HCl}$, on the prepared unstained sections. The primary antisera were treated for overnight at $4{ }^{\circ} \mathrm{C}$ in humidity chamber and then incubated with biotinylated universal secondary antibody and $\mathrm{ABC}$ reagents for $1 \mathrm{~h}$ at room temperature in humidity chamber. Finally, sections were reacted with peroxidase substrate kit for $3 \mathrm{~min}$ at room temperature. All sections were rinse in $0.01 \mathrm{M}$ PBS for three times, between each step. The primary antisera and detection kits for immunohistochemistry used in this study were described in Additional file 1: Table S1.

\section{Histomorphometry}

To observe more detailed histopathological changes, the articular cartilage injuries stained with Safranin O staining were evaluated and recorded using the Mankin scoring systems referred by the other studies [23]. With this system, the higher the score, the higher the level of OA (semiquantative scores; $\max =12$ ). The thicknesses of femur and tibia articular cartilages (micrometer per cartilage) were measured with the histomorphometrical analyses at prepared longitudinally trimmed samples, using a computer based automated image analyzer (iSolution FL ver 9.1, IMT $i$-solution Inc., Vancouver, Quebec, Canada). A total of six histological regions of femoral and tibial articular surface regions of each group were considered for further analysis. The cells occupied by over $20 \%$ of immunoreactivities, the density, of each antibody for caspase-3, PARP, TNF- $\alpha$, COX-2, IL-1 $\beta$, IFN- $\gamma$, and iNOS were regarded as positive, and the numbers of each immunoreactive cells were counted separately in each of the femoral and tibial articular surface regions as cells per square millimeter, under blinds condition.

\section{Statistical analysis}

The values were expressed as mean \pm standard deviation (SD). A multiple comparison tests were conducted for different groups. According to the result of variance homogeneity by the Levene test, one-way ANOVA test and the least-significant differences (LSD) multicomparison test were used for parametric comparison, and Kruskal-Wallis $\mathrm{H}$ test was used for non-parametric comparisons, followed by Mann-Whitney (MW) $U$ test with Bonferroni correction. Statistical analyses were conducted using SPSS for Windows (Release 14.0K, IBM SPSS Inc., USA).

\section{Results}

Although the lameness score in MP group was decreased compared to those in the other groups, there were no significant changes between groups. The lameness score was significantly decreased at 2 months and at 3 months after treatment in the PRP group and MP group when compared with the previous treatment, respectively (Fig. 1).

The focal compressive strength of the femoral and tibial articular surface cartilages were significantly decreased in the control group as compared to that of the sham group. However, the focal compressive strength significantly increased by the treatment of all three test materials. In MP group, the focal compressive strength was higher than those in any other treated groups (Fig. 2).

The Mankin scores of control group were significantly increased as compared with those of shame group. When compared with control group, it was found that the Mankin score significantly reduced with the treatment of all three test materials on the femoral and tibial articular cartilages. Especially, the Mankin score of MP treated dogs was lowest compared to those of MSC or PRP treated dogs (Table 2).

The thickness of articular cartilages was higher in the MSC and PRP than control group. The more favorable effect on the articular surface was examined 


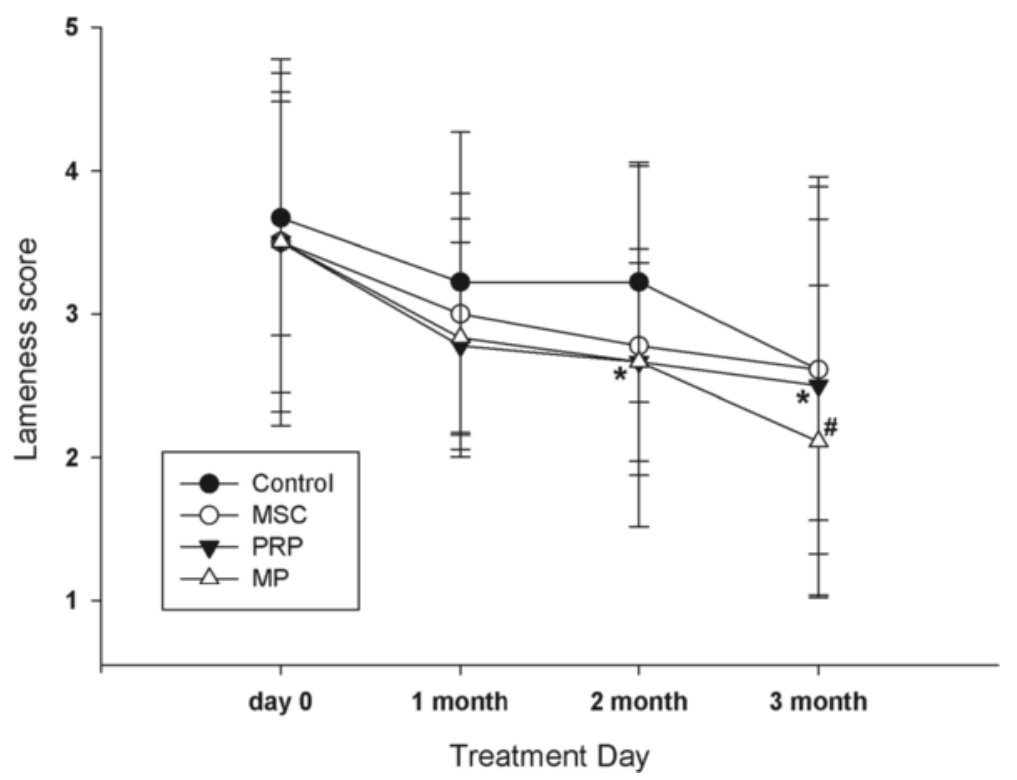

Fig. 1 The lameness score of the OA dogs. Control, treated with $1 \mathrm{ml}$ of PBS; PRP, treated with $1 \mathrm{ml}$ of PRP; MSC, treated with $1.0 \times 10^{7}$ MSC in $1 \mathrm{ml}$ of PBS; MP, treated with $1.0 \times 10^{7}$ MSC cell in $1 \mathrm{ml}$ of PRP. Asterisk indicates significantly different with day 0 within PRP group by MW test; Number sign significantly different with day 0 within MP group by MW test

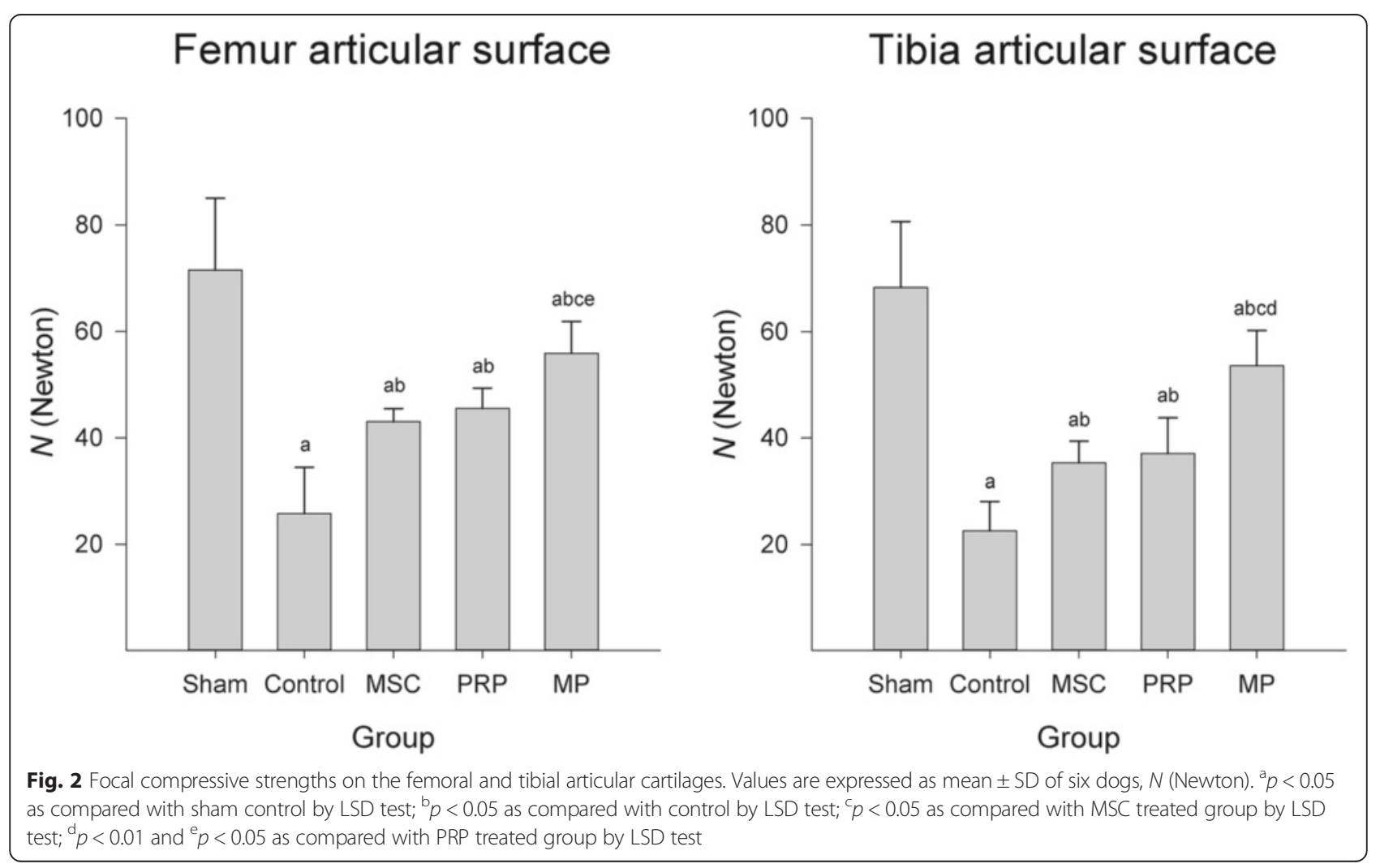


Table 2 Mankin scores on the femur and tibia articular cartilages

\begin{tabular}{|c|c|c|c|c|c|c|c|c|c|c|}
\hline \multirow[t]{2}{*}{ Groups } & \multicolumn{5}{|l|}{ Femur } & \multicolumn{5}{|l|}{ Tibia } \\
\hline & Surface damage & Hypocellularity & Clone & Stain intensity & Totalized $(\max =12)$ & Surface damage & Hypocellularity & Clone & Stain intensity & Totalized $(\max =12)$ \\
\hline Sham & $0.33 \pm 0.52$ & $0.17 \pm 0.41$ & $0.17 \pm 0.41$ & $0.33 \pm 0.52$ & $1.00 \pm 0.63$ & $0.17 \pm 0.41$ & $0.33 \pm 0.52$ & $0.17 \pm 0.41$ & $0.17 \pm 0.41$ & $0.83 \pm 1.60$ \\
\hline Control & $2.50 \pm 0.55^{a}$ & $1.67 \pm 0.52^{\mathrm{a}}$ & $1.33 \pm 0.82^{\mathrm{a}}$ & $1.67 \pm 0.52^{\mathrm{a}}$ & $7.17 \pm 1.17^{\mathrm{a}}$ & $2.17 \pm 0.41^{\mathrm{a}}$ & $2.17 \pm 0.41^{a}$ & $1.00 \pm 0.63^{\mathrm{a}}$ & $1.50 \pm 0.55^{\mathrm{a}}$ & $6.83 \pm 1.17^{\mathrm{a}}$ \\
\hline MSC & $1.00 \pm 0.63^{b c}$ & $0.83 \pm 0.41^{b c}$ & $1.17 \pm 0.41^{\mathrm{a}}$ & $1.17 \pm 0.41^{b}$ & $4.17 \pm 0.75^{\mathrm{ac}}$ & $0.67 \pm 0.52^{c}$ & $1.17 \pm 0.41^{b c}$ & $0.67 \pm 0.52$ & $1.33 \pm 0.52^{\mathrm{a}}$ & $3.83 \pm 0.75^{\mathrm{ac}}$ \\
\hline PRP & $0.83 \pm 0.41^{c}$ & $0.83 \pm 0.41^{b c}$ & $0.83 \pm 0.41^{b}$ & $1.00 \pm 0.00$ & $3.50 \pm 0.55^{\mathrm{ac}}$ & $0.50 \pm 0.55^{c}$ & $0.83 \pm 0.75^{c}$ & $0.67 \pm 0.52$ & $1.17 \pm 0.41^{\mathrm{a}}$ & $3.17 \pm 0.98^{\mathrm{ac}}$ \\
\hline MP & $0.50 \pm 0.55^{c}$ & $0.33 \pm 0.52^{c}$ & $0.33 \pm 0.52^{\text {cf }}$ & $0.33 \pm 0.52^{c f}$ & $1.50 \pm 1.38^{\mathrm{ceg}}$ & $0.33 \pm 0.52^{c}$ & $0.33 \pm 0.52^{c f}$ & $0.17 \pm 0.41^{c}$ & $0.50 \pm 0.55^{\mathrm{ceh}}$ & $1.33 \pm 1.21^{\mathrm{ceh}}$ \\
\hline
\end{tabular}

Values are expressed as mean \pm SD of six dogs
MSC mesenchymal stem cells, PRP platelet-rich plasma, MP MSC and PRP co-treatment

$M S C$ mesenchymal stem cells, $P R P$ platelet-rich plasm
${ }^{a} p<0.01$ as compared with sham control by LSD test

${ }^{\mathrm{b}} p<0.05$ as compared with sham control by LSD test

$c_{p}<0.01$ as compared with control by LSD test

${ }^{d} p<0.05$ as compared with control by LSD test

$\mathrm{e}_{p}<0.01$ as compared with MSC treated group by LSD test

${ }^{f} p<0.05$ as compared with MSC treated group by LSD test

${ }^{9} p<0.01$ as compared with PRP treated group by LSD test

${ }^{h} p<0.05$ as compared with PRP treated group by LSD test 
in MP group, compared to those of MSC and PRP groups (Fig. 3).

The contents of COL and GAG as the main component of ECM were significantly decreased in control group compared with those of sham group, but it was significantly increased in all treated groups compared with control group (Fig. 4).

When the real-time PCR performed to determine the ECM-related genes, the expression of cartilage aggrecan and SOX9 was decreased as compared with those of sham group. However, those down-regulated gene expressions were significantly increased by the treatment of all three test materials, and it was most potent in MP group (Fig. 5).

The BrdU-positive cells in the femoral and tibial articular cartilages significantly decreased in control group comparing to that of sham group. The values were significantly increased in all treated groups compared with control group. The increase of cell proliferation on the cartilage was most significant in MP group than MSC or PRP group (Fig. 6, Tables 3 and 4).

Immunopositive cells to caspase- 3 and PARP were significantly increased in the femoral and tibial cartilages of control group when compared with those of the sham

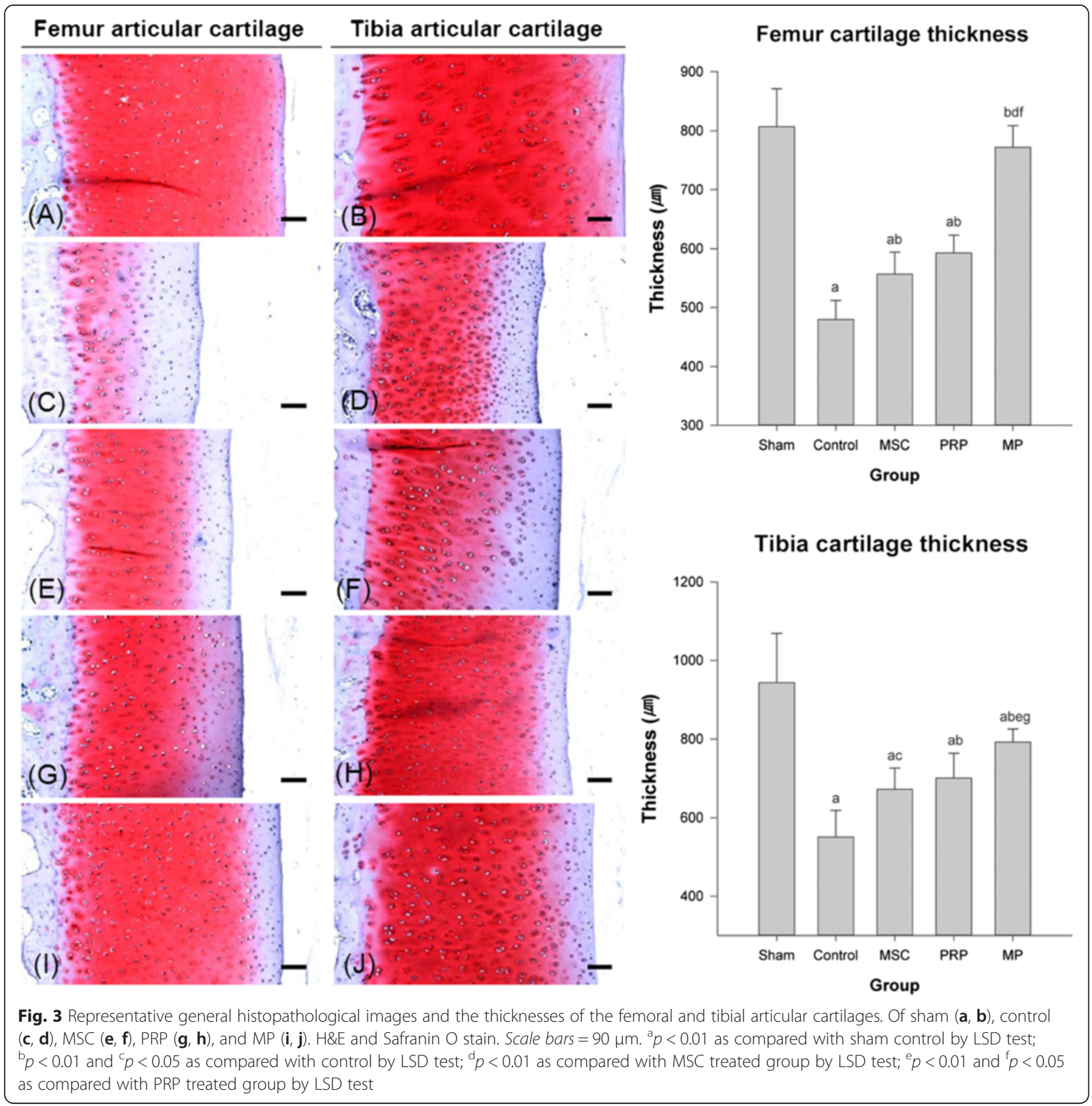




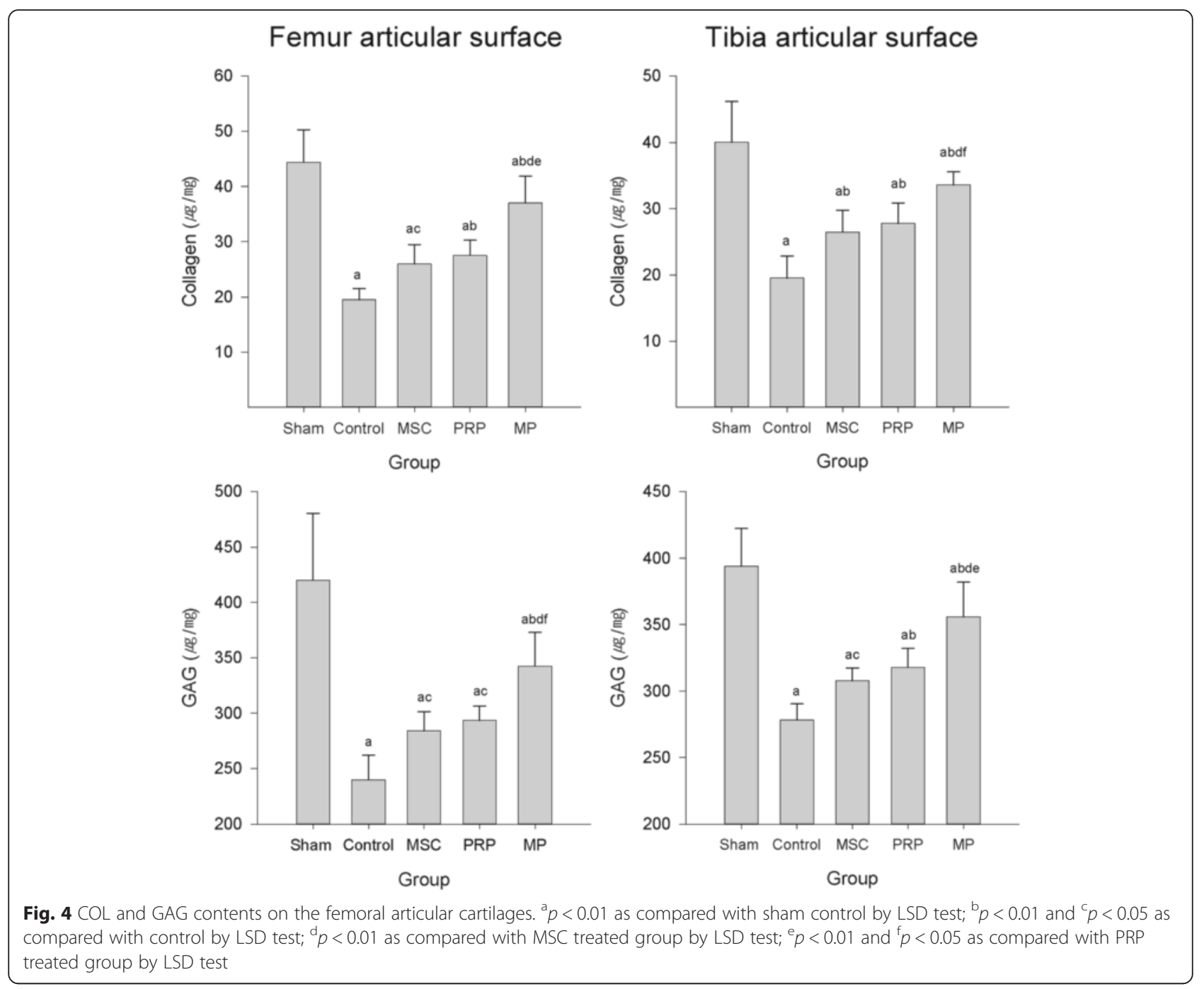

group. However, these increased cells were significantly reduced by treatment of all three test materials, and the reduction was most significant in MP group (Fig. 6, Tables 3 and 4).

TNF- $\alpha$, COX-2, IL-1 $\beta$, iNOS, and IFN- $\gamma$ staining cells were increased significantly in the femoral and tibial cartilages of control group compared with sham group. However, these increases of pro-inflammatory cytokines on the cartilages were diminished in treated groups (Fig. 6 and Additional file 1: Fig. S1-S5, Tables 3 and 4).

\section{Discussion}

Osteoarthritis (OA) is characterized by the loss of articular cartilage components with inflammation, eventually resulting in impaired joint function $[24,25]$. For this reason, this study mainly focused on the evaluation of the clinical signs, the change of ECM component and articular cartilage, the gene expression related to chondrogenesis, and the articular pathologic processes such as inflammation and apoptosis with the treatment of PRP and/or MSC.

Previously, it has been reported that the intra-articular injection of PRP reduced the lameness score [26]. Similarly, there were a meaningful decrease of lameness score with the treatment of PRP and MSC mixed with PRP in this canine OA model. Based on this result, we anticipate that PRP would relieve pain and improve articular function in an arthritic condition.

It is well known that the structure of articular cartilage is altered by the disorganization of collagen network, decrease of proteoglycan contents, and disruption of the integrity of the ECM in the process of OA [27]. Therefore, we tested the compressive strength of the articular cartilage to observe whether PRP or MSCs has a protective effect on the articular damage by OA. As previous studies have reported, Mankin score is a good index of osteoarthritis [28] and it is highly associated with compressive strength of articular cartilage [27]. We evaluated 


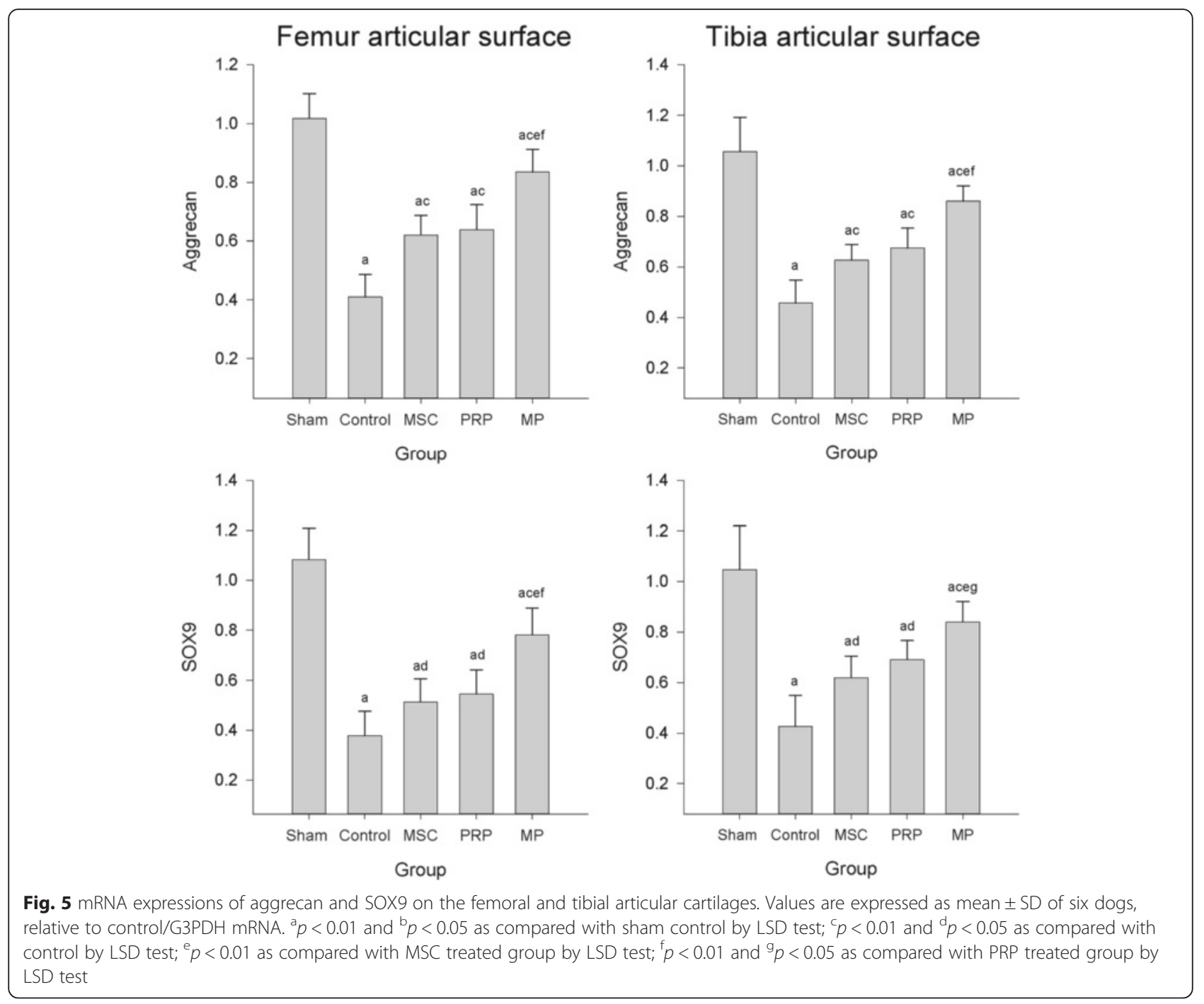

Mankin score of the affected articular cartilage. In addition, the thickness of articular cartilage and the content of COL and GAG were measured to confirm the OA condition. As a result, there were decreases in Mankin score as well as increases in the thickness of cartilage and the content of COL and GAG in the PRP and/or MSC treatment. These results suggested that PRP and MSC may have protective and regenerative effects on the degenerative cartilage of OA.

Aggrecan is known as a core protein of cartilagespecific proteoglycan, and it was reported that the mRNA expression of aggrecan was down-regulated according to the severity of OA condition $[29,30]$. The expression of SOX9, the essential transcription factor for the chondrogenic differentiation, was also inhibited by OA model [30]. In this study, the down-regulations of SOX-9 and aggrecan in the control group were increased by the MSC and PRP treatment. Based on these results, we can suppose that the increase of ECM-related factors such as aggrecan, SOX9, COL, and GAG may be closely associated with the recovery of damaged articular cartilage. From this aspect, it could be explained by the fact that PRP and/or MSC treatment was associated with the increase of focal compressive strengths and the decrease of Mankin score. These findings are compatible with a previous report indicated that the inhibition of SOX9 gene expression and the content of GAG might result in cartilage degeneration [30].

We next performed BrdU staining to examine whether the MSC and/or PRP treatment promoted the proliferation of chondrocytes. It was shown that BrdU-positive cells decreased in OA condition and increased with a treatment of MSC and/or PRP. We also performed immunostaining for the caspase-3 and PARP expression examine whether apoptotic change during OA could be affected by PRP and/or MSC treatment. Results showed that the number of caspase-3- and PARP-positive cells was increased in the OA condition and was reduced 


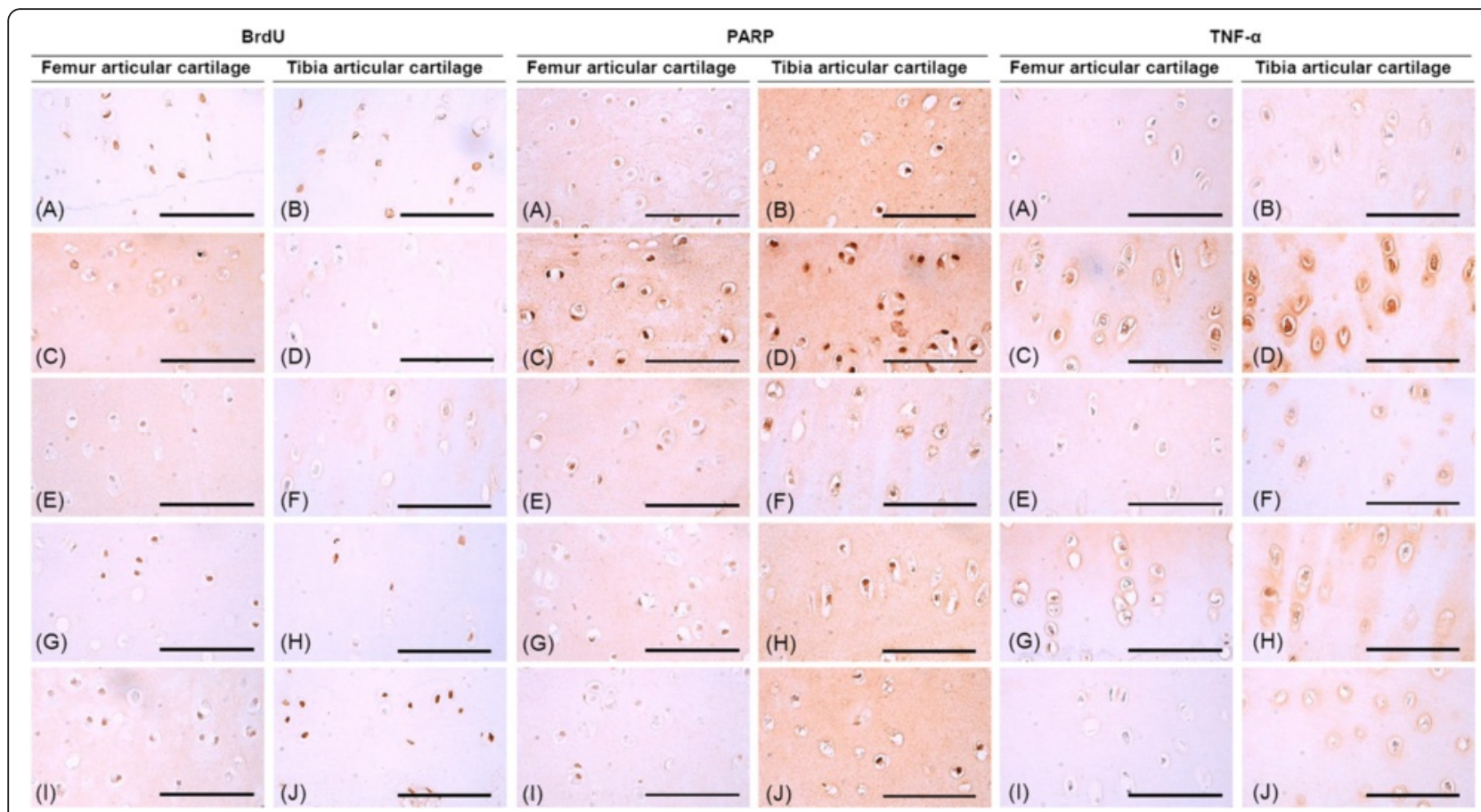

Fig. 6 Representative immunohistochemical findings of femoral and tibial articular cartilage (BrdU, TNF-a, and PARP). Of sham (a, b), control $(\mathbf{c}, \mathbf{d}), \operatorname{MSC}(\mathbf{e}, \mathbf{f}), \operatorname{PRP}(\mathbf{g}, \mathbf{h})$, and MP $(\mathbf{i}, \mathbf{j})$. Scale bars $=90 \mu \mathrm{m}$

with a treatment of MSC and/or PARP. These results were consistent with the findings of previous study that caspase-3 led to PARP to cleavage and consequently caused the progression of OA with cell apoptosis and death [31]. Therefore, we propose that the proliferation of chondrocyte may be suppressed in the process of OA through apoptotic change of articular cartilage, and this may be partly prevented by MSC and/or PRP treatment.
We examined the protein expression of cytokines relative to inflammatory reaction in the cartilage tissue. It has been known that pro-inflammatory cytokines mediated the activation of various inflammatory pathways and played a role in the progression of OA [32]. In the present study, the numbers of TNF- $\alpha-$, COX-2-, IL-1 $\beta-$, IFN- $\gamma^{-}$, and iNOS-positive cells were increased in the OA condition, and MSC and/or PRP treatment

Table 3 Immunohistochemical analysis on the femur articular cartilages

\begin{tabular}{|c|c|c|c|c|c|}
\hline Cell numbers (cells/mm²) & Sham & Control & MSC & PRP & MP \\
\hline$\overline{\mathrm{BrdU}+}$ & $144.17 \pm 47.83$ & $9.00 \pm 2.83^{f}$ & $55.00 \pm 17.34^{\mathrm{fg}}$ & $77.17 \pm 20.36^{9}$ & $129.67 \pm 31.39^{\text {fghi }}$ \\
\hline IL-1 $\beta+$ & $14.67 \pm 4.18$ & $140.50 \pm 16.69^{a}$ & $50.83 \pm 15.77^{\mathrm{ab}}$ & $44.50 \pm 13.66^{\mathrm{ab}}$ & $23.50 \pm 7.87^{\mathrm{bcd}}$ \\
\hline TNF-a+ & $5.50 \pm 4.09$ & $103.00 \pm 18.70^{f}$ & $55.33 \pm 18.91^{\mathrm{fg}}$ & $38.00 \pm 10.16^{\mathrm{fg}}$ & $13.83 \pm 3.66^{\mathrm{ghi}}$ \\
\hline $\operatorname{cox}-2+$ & $16.33 \pm 2.73$ & $102.67 \pm 22.57^{f}$ & $65.50 \pm 10.21^{\mathrm{fg}}$ & $44.50 \pm 10.21^{\mathrm{fg}}$ & $23.67 \pm 6.92^{g h i}$ \\
\hline iNOS+ & $57.83 \pm 15.82$ & $196.67 \pm 42.57^{a}$ & $106.50 \pm 17.60^{\mathrm{ab}}$ & $66.17 \pm 10.53^{b}$ & $40.33 \pm 12.40^{\text {bce }}$ \\
\hline Caspase-3+ & $16.50 \pm 8.87$ & $80.33 \pm 11.22^{a}$ & $52.17 \pm 12.62^{\mathrm{ab}}$ & $46.17 \pm 11.86^{\mathrm{ab}}$ & $18.00 \pm 8.46^{\mathrm{bcd}}$ \\
\hline PARP+ & $30.00 \pm 11.92$ & $101.17 \pm 21.64^{a}$ & $64.17 \pm 14.63^{\mathrm{ab}}$ & $54.50 \pm 13.16^{\mathrm{ab}}$ & $32.50 \pm 10.31^{\text {bce }}$ \\
\hline IFN- $-\gamma+$ & $5.33 \pm 3.27$ & $88.33 \pm 13.35^{\mathrm{a}}$ & $47.17 \pm 11.51^{\mathrm{ab}}$ & $31.17 \pm 15.28^{\mathrm{ab}}$ & $12.50 \pm 2.88^{\mathrm{bcd}}$ \\
\hline
\end{tabular}

Values are expressed as mean \pm SD of six dogs

MSC mesenchymal stem cells, PRP platelet-rich plasma, MP MSC and PRP co-treatment

${ }^{a} p<0.01$ as compared with sham control by LSD test

${ }^{\mathrm{b}} p<0.01$ as compared with control by LSD test

${ }^{c} p<0.01$ as compared with MSC treated group by LSD test

$\mathrm{d}_{p}<0.01$ as compared with PRP treated group by LSD test

$\mathrm{e}_{p}<0.05$ as compared with PRP treated group by LSD test

${ }^{f} p<0.01$ as compared with sham control by MW test

${ }^{9} p<0.01$ as compared with control by MW test

$\mathrm{h}_{p}<0.01$ as compared with MSC treated group by MW test

i $p<0.01$ as compared with PRP treated group by MW test 
Table 4 Immunohistochemical analysis on the tibia articular cartilages

\begin{tabular}{lcclll}
\hline Cell numbers (cells $/ \mathrm{mm}^{2}$ ) & Sham & Control & MSC & PRP & MP \\
\hline BrdU+ & $123.67 \pm 24.40$ & $7.00 \pm 2.97^{\mathrm{h}}$ & $49.50 \pm 12.69^{\mathrm{hj}}$ & $62.00 \pm 16.09^{\mathrm{hj}}$ & $120.33 \pm 29.27^{\mathrm{jkl}}$ \\
IL-1 $\beta+$ & $5.33 \pm 2.16$ & $170.67 \pm 19.94^{\mathrm{a}}$ & $63.50 \pm 11.64^{\mathrm{ac}}$ & $41.33 \pm 16.10^{\mathrm{ac}}$ & $15.67 \pm 10.25^{\mathrm{cdf}}$ \\
TNF-a+ & $6.33 \pm 3.14$ & $141.00 \pm 32.51^{\mathrm{a}}$ & $70.33 \pm 14.17^{\mathrm{ac}}$ & $53.33 \pm 15.24^{\mathrm{ac}}$ & $28.50 \pm 10.45^{\mathrm{bcdg}}$ \\
COX-2+ & $4.00 \pm 2.61$ & $129.67 \pm 44.74^{\mathrm{h}}$ & $61.67 \pm 13.76^{\mathrm{hj}}$ & $37.50 \pm 11.04^{\mathrm{hj}}$ & $18.33 \pm 3.93^{\mathrm{hjkl}}$ \\
iNOS+ & $41.17 \pm 17.88$ & $243.00 \pm 54.32^{\mathrm{h}}$ & $124.33 \pm 45.37^{\mathrm{hj}}$ & $73.00 \pm 10.97^{\mathrm{jj}}$ & $47.60 \pm 13.17^{\mathrm{ikl}}$ \\
Caspase-3+ & $6.00 \pm 3.85$ & $102.50 \pm 27.06^{\mathrm{h}}$ & $43.17 \pm 12.48^{\mathrm{hj}}$ & $25.83 \pm 5.53^{\mathrm{hj}}$ & $15.33 \pm 4.63^{\mathrm{hjk}}$ \\
PARP+ & $45.67 \pm 10.63$ & $134.67 \pm 38.53^{\mathrm{a}}$ & $68.33 \pm 17.49^{\mathrm{c}}$ & $63.33 \pm 19.03^{\mathrm{c}}$ & $39.67 \pm 12.36^{\mathrm{ceg}}$ \\
IFN- + & $7.50 \pm 2.43$ & $49.67 \pm 11.40^{\mathrm{h}}$ & $28.33 \pm 5.79^{\mathrm{hj}}$ & $22.33 \pm 3.27^{\mathrm{hj}}$ & $13.83 \pm 3.82^{\mathrm{jkl}}$ \\
\hline
\end{tabular}

Values are expressed as mean \pm SD of six dogs

MSC mesenchymal stem cells, PRP platelet-rich plasma, MP MSC and PRP co-treatment

${ }^{a} p<0.01$ as compared with sham control by LSD test

${ }^{\mathrm{b}} p<0.05$ as compared with sham control by LSD test

${ }^{c} p<0.01$ as compared with control by LSD test

${ }^{\mathrm{d}} p<0.01$ as compared with MSC treated group by LSD test

e $p<0.05$ as compared with MSC treated group by LSD test

${ }^{f} p<0.01$ as compared with PRP treated group by LSD test

${ }^{9} p<0.05$ as compared with PRP treated group by LSD test

${ }^{\mathrm{h}} p<0.01$ as compared with sham control by MW test

i $p<0.05$ as compared with sham control by MW test

${ }^{\mathrm{j}} p<0.01$ as compared with control by MW test

${ }^{\mathrm{k}} p<0.01$ as compared with MSC treated group by MW test

I $p<0.01$ as compared with PRP treated group by MW test

stimulated the down-regulated expression of inflammatory cytokines. This result is comparable to the previous studies that MSC increased the anti-inflammatory cytokines such as IL-10, and PRP also had anti-inflammatory effect via blockage of NF- $\mathrm{KB}$ cascade, which contributes to the up-regulation of pro-inflammatory cytokines [33]. It has been known that MSC played important role in the cartilage repair by direct differentiation to chondrocyte and paracrine effect $[8,34]$. In addition, it also has been reported that PRP could promote the proliferation by its various growth factors rather than differentiation of MSCs [35]. Therefore, PRP might prevent the depletion of MSCs, enhance the effect of MSCs, and guide MSCs to properly differentiate into chondrocytes. Consistent with previous study, the results of this study suggested that each treated with either MSC or PRP could decrease death or apoptosis of chondrocytes and inhibit inflammatory response $[31,36]$ and that the cotreatment with MSC and PRP might have beneficial effects on the pathologic changes in the articular cartilage.

In summary, we have shown that MSC and/or PRP ameliorated the degeneration of articular cartilage in the surgically induced OA animal model. The proliferation of chondrocyte may be suppressed in the process of OA through apoptotic change of articular cartilage, and this may be partly prevented by MSC and/or PRP treatment. MSC and/or PRP treatment also stimulated the down-regulated expression of inflammatory cytokines such as TNF- $\alpha-$, COX-2-, IL$1 \beta-$, IFN- $\gamma^{-}$, and iNOS. It will be needed to elucidate if transplanted MSCs are engrafted and differentiated to chondrocyte in OA cartilage and how MSCs and PRP interact in intra-articular environment.

\section{Conclusions}

Taken together, this study shows that the combination of MSC and PRP has a beneficial and synergistic effect on $\mathrm{OA}$ via the ECM synthesis and chondrocyte proliferation and via the anti-inflammatory reaction. Therefore, the combination treatment of MSC and PRP may be very useful as an inflammatory regulator for the treatment of OA that exhibit irreversible articular degeneration.

\section{Ethics approval and consent to participate}

All procedures were approved (KNU2015-060) by the Institutional Animal Care and Use Committees of Kyungpook National University.

\section{Additional file}

Additional file 1: This contains Figures S1-S6 and Table S1. Fig. S1-
S5) Representative images of IL-1 $\beta+$, COX-2+, iNOS+, Caspase-3+
and IFN- $\gamma+$ cells, Fig. S6) Result of FACS analysis, Table S1) Primary
antisera and detection kits for immunohistochemistry used in this
study

\section{Abbreviations}

BrdU: 5-bromo-2'-deoxyuridine; CD: cluster of differentiation; COX: cyclooxygenase; ECM: extracellular matrix; GAG: glycosaminoglycan; IFN: interferon; IL: interleukin; iNOS: inducible nitric oxide synthase; LSD: least-significant differences; MSC: mesenchymal stem cell; MW: Mann-Whitney; OA: osteoarthritis; PARP: cleaved poly (ADP-ribose) polymerase; PBS: phosphate-buffered saline; PRP: platelet-rich plasma; TNF: tumor necrosis factor. 


\section{Competing interests}

The authors declare that they have no competing interests.

\section{Authors' contributions}

SY and YSK built the idea and protocols of this paper and wrote the manuscript. SKK participated in data collection and analysis. All authors approved this manuscript.

\section{Author details}

'Department of Veterinary Surgery, College of Veterinary Medicine, Kyungpook National University, Daegu 702-701, Republic of Korea. 2Department of Anatomy and Histology, College of Korean Medicine, Daegu Haany University, Gyeongsan 712-715, Republic of Korea. ${ }^{3}$ Stem Cell Therapeutic Research Institute, Kyungpook National University, Daegu 702-701, Republic of Korea.

Received: 6 November 2015 Accepted: 6 January 2016

\section{Published online: 15 January 2016}

\section{References}

1. Goldring MB, Goldring SR. Osteoarthritis. J Cell Physiol. 2007:213:626-34

2. Lo GH, LaValley M, McAlindon T, Felson DT. Intra-articular hyaluronic acid in treatment of knee osteoarthritis: a meta-analysis. JAMA. 2003;290:3115-21.

3. Arrich J, Piribauer F, Mad P, Schmid D, Klaushofer K, Mullner M. Intraarticular hyaluronic acid for the treatment of osteoarthritis of the knee: systematic review and meta-analysis. CMAJ. 2005;172:1039-43.

4. Tamura T, Ohmori K. Rhein, an active metabolite of diacerein, suppresses the interleukin-1 alpha-induced proteoglycan degradation in cultured rabbit articular chondrocytes. Jpn J Pharmacol. 2001;85:101-4.

5. Lin L, Zhou C, Wei X, Hou Y, Zhao L, Fu X, et al. Articular cartilage repair using dedifferentiated articular chondrocytes and bone morphogenetic protein 4 in a rabbit model of articular cartilage defects. Arthritis Rheum. 2008:58:1067-75

6. Marlovits S, Hombauer M, Truppe M, Vecsei V, Schlegel W. Changes in the ratio of type-I and type-II collagen expression during monolayer culture of human chondrocytes. J Bone Joint Surg (Br). 2004;86:286-95.

7. Nganvongpanit K, Pothacharoen P, Chaochird P, Klunklin K, Warrit K, Settakorn J, et al. Prospective evaluation of serum biomarker levels and cartilage repair by autologous chondrocyte transplantation and subchondral drilling in a canine model. Arthritis Res Ther. 2009;11:R78-8.

8. Jo CH, Lee $Y G$, Shin WH, Kim H, Chai JW, Jeong EC, et al. Intra-articular injection of mesenchymal stem cells for the treatment of osteoarthritis of the knee: a proof-of-concept clinical trial. Stem Cells. 2014:32:1254-66.

9. Sekiya I, Ojima M, Suzuki S, Yamaga M, Horie M, Koga H, et al. Human mesenchymal stem cells in synovial fluid increase in the knee with degenerated cartilage and osteoarthritis. J Orthop Res. 2011;30:943-9.

10. Murphy JM, Dixon K, Beck S, Fabian D, Feldman A, Barry F. Reduced chondrogenic and adipogenic activity of mesenchymal stem cells from patients with advanced osteoarthritis. Arthritis Rheum. 2002:46:704-13.

11. Barry F, Murphy M. Mesenchymal stem cells in joint disease and repair. Nat Rev Rheumatol. 2013;9:584-94.

12. Metcalf KB, Mandelbaum BR, Mcllwraith CW. Application of platelet-rich plasma to disorders of the knee joint. Cartil. 2013;4:295-312

13. Bendinelli P, Matteucci E, Dogliotti G, Corsi MM, Banfi G, Maroni P, et al. Molecular basis of anti-inflammatory action of platelet-rich plasma on human chondrocytes: mechanisms of NF-kappaB inhibition via HGF. J Cell Physiol. 2010;225:757-66

14. El-Sharkawy H, Kantarci A, Deady J, Hasturk H, Liu H, Alshahat M, et al. Platelet-rich plasma: growth factors and pro- and anti-inflammatory properties. J Periodontol. 2007:78:661-9.

15. Danisovic L, Varga I, Polak S. Growth factors and chondrogenic differentiation of mesenchymal stem cells. Tissue Cell. 2011:44:69-73.

16. Demidova-Rice TN, Wolf L, Deckenback J, Hamblin MR, Herman IM. Human platelet-rich plasma- and extracellular matrix-derived peptides promote impaired cutaneous wound healing in vivo. PLOS ONE. 2012:7:e32146.

17. Zhang N, Wu YP, Qian SJ, Teng C, Chen S, Li H. Research progress in the mechanism of effect of PRP in bone deficiency healing. Sci World J. 2013.

18. Bennett D, Eckersall PD, Waterston M, Marchetti V, Rota A, McCulloch E, et al. The effect of robenacoxib on the concentration of C-reactive protein in synovial fluid from dogs with osteoarthritis. BMC Vet Res. 2013;9:42.
19. Warnock JJ, Baltzer WI, Duesterdieck-Zellmer K, Ott J. Minimally invasive synovium harvest for potential use in meniscal tissue engineering. Res Vet Sci. 2012;93:1472-80

20. Warnock JJ, Spina J, Bobe G, Duesterdieck-Zellmer KF, Ott J, Baltzer WI, et al. Culture of canine synoviocytes on porcine intestinal submucosa scaffolds as a strategy for meniscal tissue engineering for treatment of meniscal injury in dogs. Vet J. 2014;199:49-56.

21. Reddy GK, Enwemeka CS. A simplified method for the analysis of hydroxyproline in biological tissues. Clin Biochem. 1996;29:225-9.

22. Ignat'eva NY, Danilov NA, Averkiev SV, Obrezkova MV, Lunin W, Sobol' EN. Determination of hydroxyproline in tissues and the evaluation of the collagen content of the tissues. J Anal Chem. 2007;62:51-7.

23. van der Sluijs JA, Geesink RG, van der Linden AJ, Bulstra SK, Kuyer R, Drukker J. The reliability of the Mankin score for osteoarthritis. J Orthop Res. 1992;10:58-61.

24. Qin J, Liu YS, Liu J, Li J, Tan Y, Li XJ, et al. Effect of angelica sinensis polysaccharides on osteoarthritis in vivo and in vitro: a possible mechanism to promote proteoglycans synthesis. Evid Based Complement Alternat Med. 2013.

25. Na JY, Song KB, Kim S, Kwon YB, Kim DG, Lee JK, et al. Effects of HPL-04 on degenerative osteoarthritis. J Korean Soc Food Sci Nutr. 2014;43:30-9.

26. Kon E, Buda R, Filardo G, Di Martino A, Timoncini A, Cenacchi A, et al. Platelet-rich plasma: intra-articular knee injections produced favorable results on degenerative cartilage lesions. Knee Surg Sports Traumatol Arthrosc. 2010;18:472-9.

27. Franz T, Hasler EM, Hagg R, Weiler C, Jakob RP, Mainil-Varlet P. In situ compressive stiffness, biochemical composition, and structural integrity of articular cartilage of the human knee joint. Osteoarthr Cartil. 2001;9:582-92.

28. Pauli C, Whiteside R, Heras FL, Nesic D, Koziol J, Grogan SP, et al. Comparison of cartilage histopathology assessment systems on human knee joints at all stages of osteoarthritis development. Osteoarthr Cartil. 2012;20:476-85.

29. Lorenz H, Wenz W, Ivancic M, Steck E, Richter W. Early and stable upregulation of collagen type II, collagen type I and YKL40 expression levels in cartilage during early experimental osteoarthritis occurs independent of joint location and histological grading. Arthritis Res Ther. 2005;7:R156-65.

30. Yagi R, McBurney D, Laverty D, Weiner S, Horton Jr WE. Intrajoint comparisons of gene expression patterns in human osteoarthritis suggest a change in chondrocyte phenotype. J Orthop Res. 2005:23:1128-38.

31. Shakibaei M, John T, Seifarth C, Mobasheri A. Resveratrol inhibits IL-1 betainduced stimulation of caspase-3 and cleavage of PARP in human articular chondrocytes in vitro. Ann N Y Acad Sci. 2007;1095:554-63.

32. Goldring MB. The role of the chondrocyte in osteoarthritis. Arthritis Rheum. 2000:43:1916-26.

33. Andia I, Maffulli N. Platelet-rich plasma for managing pain and inflammation in osteoarthritis. Nat Rev Rheumatol. 2013:9:721-30.

34. Chung JY, Song M, Ha CW, Kim JA, Lee CH, Park YB. Comparison of articular cartilage repair with different hydrogel-human umbilical cord blood-derived mesenchymal stem cell composites in a rat model. Stem Cell Res Ther. 2014;5:39.

35. Mishra A, Tummala P, King A, Lee B, Kraus M, Tse V, et al. Buffered plateletrich plasma enhances mesenchymal stem cell proliferation and chondrogenic differentiation. Tissue Eng Part C Methods. 2009:15:431-5.

36 Pereira RC, Scaranari M, Benelli R, Strada P, Reis RL, Cancedda R, et al. Dual effect of platelet lysate on human articular cartilage: a maintenance of chondrogenic potential and a transient proinflammatory activity followed by an inflammation resolution. Tissue Eng Part A. 2013;19:1476-88.

\section{Submit your next manuscript to BioMed Central and we will help you at every step:}

- We accept pre-submission inquiries

- Our selector tool helps you to find the most relevant journal

- We provide round the clock customer support

- Convenient online submission

- Thorough peer review

- Inclusion in PubMed and all major indexing services

- Maximum visibility for your research

Submit your manuscript at www.biomedcentral.com/submit
) Biomed Central 